\title{
Maxillofacial Radiology 165
}

SADJ October 2018, Vol. 73 No. 9 p576

\section{CJ Nortjé}

A 30-year old female presented with a swelling extending between 35 and 43, which had grown over the past ten months (Figs. A,B,C), with intermittent pain. Figures D,E,F show a similar case in a 15 year old male patient. Describe the radiological features and list your differential diagnosis.

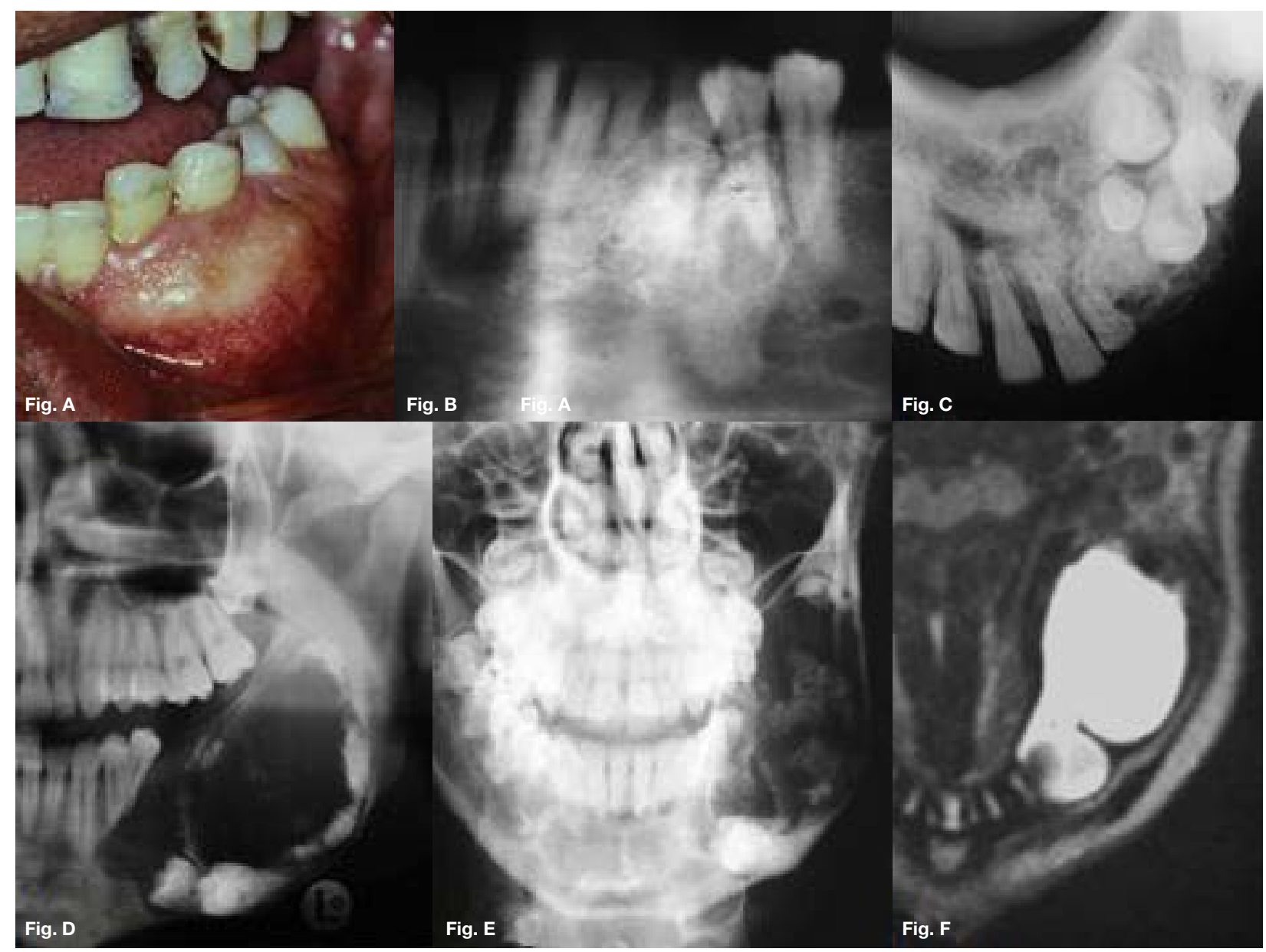

\section{INTERPRETATION}

The cropped pantomograph (Fig.B) shows a multilocular radiolucency of an expansive tumour containing varying calcifications. Figures D\&E show a well demarcated multilocular lesion in the body/ramus region of the left mandible, with two displaced molar teeth, resorption of the roots of 34 and 35 and tooth-like calcifications at the borders of the lesion. The coronal T2 MRI image (Fig.F) shows a multilocular hyper-intense lesion, with no discernible calcifications. Diagnosis: the rare tumour, odonto-ameloblastoma (OA), first reported by Kemper and Root (1944). Shafer et al (1983) described this as an odontogenic neoplasm of mixed tissue origin, consistent with both ameloblastoma and odontoma. Histologically, a typical ameloblastoma component whilst the odontoma element may be either compound or complex. Shafer et al (1983) emphasized that this is one neoplastic process with relatively highly undifferentiated tissues. Occurring most commonly in the second decade of life, it may vary in size. Smaller lesions occur between the teeth, confined

CJ Nortjé: $B C h D, P h D, A B O M R$, DSc. Faculty of Dentistry, University of the Western Cape. E-mail: cnortje@uwc.ac.za to the alveolar bone between the crest of the ridge and the teeth apices (Figs. A,B\&C). Buccal expansion of the cortex is common, even for smaller lesions. The odontoma component presents various stages of development, early lesions being radiolucent with radiopaque flecks. More mature lesions are better developed odontoma, resembling teeth or as a nonspecific complex odontoma mass. Importantly, this is an aggressive tumour, treated precisely as an ameloblastoma. The differential diagnosis should include: ameloblastic fibro-odontoma, Pinborg tumour, calcifying odontogenic cyst and adenomatoid odontogenic tumour.

\section{References}

1. Kemper J, Root R: Adamanto-odontoma: report of a case. Am J Orthodont Oral Surg. 30: 709, 1944.

2. Shafer WG, Hine K, Levy BM: A textbook of Oral Pathology, $4^{\text {th }}$ Ed. Philadelphia: WB Saunders, 1983, p.311.

3. Thompson IO, Phillips VM, Ferreira R, Housego TG. Odontoameloblastoma: A case report. Br J Oral Maxillofacial Surg. 1990;28:347-9. 